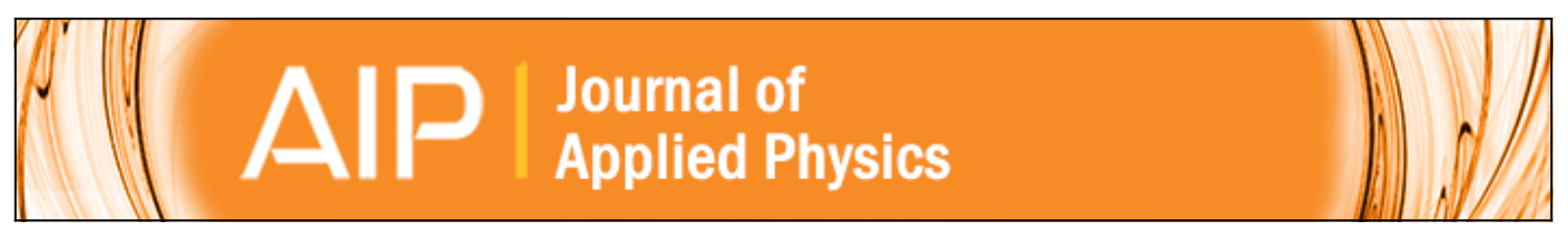

\title{
Physical mechanism of progressive breakdown in gate oxides
}

Felix Palumbo, Salvatore Lombardo, and Moshe Eizenberg

Citation: Journal of Applied Physics 115, 224101 (2014); doi: 10.1063/1.4882116

View online: http://dx.doi.org/10.1063/1.4882116

View Table of Contents: http://scitation.aip.org/content/aip/journal/jap/115/22?ver=pdfcov

Published by the AIP Publishing

\section{Articles you may be interested in}

Percolation path and dielectric-breakdown-induced-epitaxy evolution during ultrathin gate dielectric breakdown transient

Appl. Phys. Lett. 83, 2223 (2003); 10.1063/1.1611649

Low-temperature formation of highly reliable silicon-nitride gate dielectrics with suppressed soft-breakdown phenomena for advanced complementary metal-oxide-semiconductor technology

J. Vac. Sci. Technol. B 20, 1406 (2002); 10.1116/1.1491550

Soft-breakdown-suppressed ultrathin atomic-layer-deposited silicon-nitride/SiO 2 stack gate dielectrics for advanced complementary metal-oxide-semiconductor technology

Appl. Phys. Lett. 79, 3488 (2001); 10.1063/1.1420586

Application of linear elastic fracture mechanics on electric discharge breakdown in interconnects

Appl. Phys. Lett. 73, 3565 (1998); 10.1063/1.122808

Reliability characterization of ultra-thin film dielectrics

AIP Conf. Proc. 449, 115 (1998); 10.1063/1.56786

\section{AlP Re-register for Table of Content Alerts}




\title{
Physical mechanism of progressive breakdown in gate oxides
}

\author{
Felix Palumbo, ${ }^{1, a)}$ Salvatore Lombardo, ${ }^{2}$ and Moshe Eizenberg ${ }^{1}$ \\ ${ }^{1}$ Department of Materials Science and Engineering, Technion - Israel Institute of Technology, \\ 32000 Haifa, Israel \\ ${ }^{2}$ Istituto per la Microelettronica e Microsistemi (IMM) - Consiglio Nazionale delle Ricerche (CNR), \\ Zona Industriale, Ottava Strada, 5, 95121 Catania, Italy
}

(Received 7 April 2014; accepted 27 May 2014; published online 9 June 2014)

\begin{abstract}
The definition of the basic physical mechanisms of the dielectric breakdown (BD) phenomenon is still an open area of research. In particular, in advanced complementary metal-oxide-semiconductor (CMOS) circuits, the BD of gate dielectrics occurs in the regime of relatively low voltage and very high electric field; this is of enormous technological importance, and thus widely investigated but still not well understood. Such BD is characterized by a gradual, progressive growth of the gate leakage through a localized BD spot. In this paper, we report for the first time experimental data and a model which provide understanding of the main physical mechanism responsible for the progressive $\mathrm{BD}$ growth. We demonstrate the ability to control the breakdown growth rate of a number of gate dielectrics and provide a physical model of the observed behavior, allowing to considerably improve the reliability margins of CMOS circuits by choosing a correct combination of voltage, thickness, and thermal conductivity of the gate dielectric. (C) 2014 AIP Publishing LLC. [http://dx.doi.org/10.1063/1.4882116]
\end{abstract}

\section{INTRODUCTION}

The studies on dielectric breakdown (BD) belong to a long record of major advancements in science and technology. Though the progress in this field has been impressive, the BD phenomenon taking place when voltage differences of the order of $1 \mathrm{~V}$ are applied to short distances, of the order of nanometers, i.e., with very large electric fields but insufficient energy to produce either impact-ionization, or plasmonic loss, $\mathrm{H}$ release, or other quantum effects, is still not well understood. Nevertheless, this is a major area for the progress of nanotechnology. For example, the reliability of ultrathin gate dielectrics is a crucial issue for the scaling of transistors of very large scale integrated (VLSI) circuits realized in complementary metal-oxide-semiconductor (CMOS) technology. Ultra-thin gate oxides exhibit a gradual loss of their insulating properties when a breakdown path is generated by a high voltage stress. In CMOS circuits, at their operation voltages, this progressive BD (PBD) can be very slow with respect to the conditions of standard high voltage gate stack wear-out accelerated tests. Under operation conditions it may take many years to reach gate leakage levels large enough to appreciably disturb the circuit operation, improving thus the reliability margins of CMOS applications. ${ }^{1-3}$ Moreover, a new area of application of the $\mathrm{BD}$ in thin dielectrics is the resistive switching phenomenon, ${ }^{4,5}$ of large interest for the realization of new generations of ultra-scaled low power non-volatile semiconductor memories.

Despite the success to predict the statistics, ${ }^{6,7}$ the conduction, ${ }^{8,9}$ and the micro-structural damage within the transistor structures during the progressive BD regime, ${ }^{3,10-12}$ all these phenomenological descriptions do not reveal the fundamental physical mechanism that drives the progressive increase of the current after the initial BD event. One of the

${ }^{a)}$ E-mail: palumbo@mt.technion.ac.il. Phone: +972-4-829 2779. major features of the rate of increase of the BD current is that it is characterized by a strong voltage dependence at low voltages. ${ }^{1,3,9}$ Such an effect, initially observed only in Poly$\mathrm{Si} / \mathrm{SiO}_{\mathrm{x}} \mathrm{N}_{\mathrm{y}} / \mathrm{Si} \mathrm{MOS}$ systems, was later found to occur also in Si CMOS gate stacks with metal gate and high permittivity $(\text { high-K })^{3}$ dielectric. It is therefore most likely a general physical phenomenon taking place in dielectric breakdown at relatively low voltages.

At high voltages, the BD transients are extremely fast. In the case of Poly- $\mathrm{Si} / \mathrm{SiO}_{\mathrm{x}} \mathrm{N}_{\mathrm{y}} / \mathrm{Si} \mathrm{MOS}$ stacks, it was shown that there is a voltage threshold at about $4.5 \mathrm{~V}$ above which the dynamics of the $\mathrm{BD}$ growth changes abruptly, with $\mathrm{BD}$ growth rates above $1 \times 10^{+6} \mathrm{~A} / \mathrm{s} .{ }^{13}$ At a lower voltage, the $\mathrm{BD}$ growth rate becomes many orders of magnitude lower. In this regime, the dissipated power is below $\approx 1 \mathrm{~mW}$; by using three-dimensional heat flow simulations it has been shown that the $\mathrm{BD}$ cannot produce complete melting in the $\mathrm{BD}$ spot region. This is consistent with the onset of slow BD transients below the above mentioned voltage threshold. ${ }^{14}$

The initial works on poly- $\mathrm{Si} / \mathrm{SiO}_{\mathrm{x}} \mathrm{N}_{\mathrm{y}} / \mathrm{Si}$ gate stacks were later extended to the area of MOS stacks with metal gates and gate oxides such as $\mathrm{SiO}_{2}, \mathrm{SiO}_{\mathrm{x}} \mathrm{N}_{\mathrm{y}}$, and/or high $\mathrm{k}$ dielectrics on Si substrates. ${ }^{3,15,16}$ On large area capacitor samples with tungsten metal gates on $\mathrm{SiO}_{2}$ dielectrics during CVS (constant voltage stress) experiments, it was found that the PBD phase is observed only when the current level through the BD spot during the CVS is below $1-10 \mu \mathrm{A},{ }^{15-17}$ barely distinguishable from the background gate leakage current. When such a level of BD current is reached, a fast BD runaway takes place and the BD current suddenly jumps to the $\mathrm{mA}$ level. This is very different from the case of poly- $\mathrm{Si} / \mathrm{SiO}_{\mathrm{x}} \mathrm{N}_{\mathrm{y}} / \mathrm{Si}$ gate stacks, where the $\mathrm{PBD}$ is seen even at current levels of the order of $100 \mu \mathrm{A} .{ }^{1}$ Later on, on small area silicon nFET samples with TiN metal gates on $\mathrm{HfO}_{2}$ dielectrics with an ultra-thin interfacial $\mathrm{SiO}_{2}$ layer, during 
CVS experiments the PBD phase was much more clearly manifested and studied since the background gate leakage current was smaller because of the smaller gate area and of the presence of the high-k dielectric. ${ }^{15,18}$ In any case, also in these systems when the $\mathrm{BD}$ current reached the 1-10 $\mu \mathrm{A}$ level, the PBD was overwhelmed by a fast BD runaway and the $\mathrm{BD}$ current suddenly jumps to the $\mathrm{mA}$ level. So the PBD phenomenology, though with differences in the various cases, appears to be a general effect in dielectrics stressed at large electric fields, at least in the case of samples with $\mathrm{Si}$ substrates.

In this paper, we show that the same type of PBD phenomenology is observed also in samples with InGaAs substrates with high-k dielectrics and metal gates. From this further observation, and considering that therefore the PBD phenomenology is found with different electrodes such as Poly-Si and metal, with different gate oxides such as $\mathrm{SiO}_{2}$, $\mathrm{SiO}_{\mathrm{x}} \mathrm{N}_{\mathrm{y}}$, or high-k dielectrics, and with different substrates such as Si or an InGaAs, we conclude that PBD is a very general physical effect. While the phenomenology is therefore quite well defined, and observed with many different materials, the understanding of what is the leading physical mechanism at low voltage causing the progressive BD growth is still lacking. To clarify such a mechanism, it is therefore particularly interesting to investigate the energy transfer mechanism from the BD path to its surroundings. To achieve this objective, the BD transients on different dielectric layers in MOS structures were compared to provide direct experimental information about the BD transient. The difference in the thermal properties of the dielectric layers should reveal the real impact of the thermal properties on the BD event. In this work, we demonstrate and model this aspect, providing for the first time a physical model of progressive BD.

\section{EXPERIMENTAL}

A number of MOS structures were fabricated with different dielectric layers: $\mathrm{Al}_{2} \mathrm{O}_{3}, \mathrm{Si}_{3} \mathrm{~N}_{4}$ and $\mathrm{HfO}_{2}$. In all cases, an n-type InGaAs substrate (epitaxially grown on InP wafers) and gate metallization of $\operatorname{Ti}(1 \mathrm{~nm}) / \mathrm{Au}(200 \mathrm{~nm})$ were used. The area of the devices was $1.1 \times 10^{-4} \mathrm{~cm}^{2}$.

For the MOS structure with $\mathrm{Al}_{2} \mathrm{O}_{3}$ dielectric layer, a pre-dielectric deposition treatment (PDT) was performed by a $\mathrm{NH}_{4} \mathrm{OH}$ solution, and then a $9 \mathrm{~nm}$ thick $\mathrm{Al}_{2} \mathrm{O}_{3}$ layer was prepared by atomic layer deposition (ALD) using trimethylaluminium (TMA) and $\mathrm{H}_{2} \mathrm{O}$ precursors at $300^{\circ} \mathrm{C}$. For the MOS structures with $\mathrm{Si}_{3} \mathrm{~N}_{4}$, the dielectric was deposited by plasma enhanced chemical vapor deposition (PECVD) with $\mathrm{NH}_{3}$ pre-deposition treatments. For the MOS structures with $\mathrm{HfO}_{2}$, a PDT was performed and then a $10 \mathrm{~nm} \mathrm{HfO}_{2}$ layer was prepared by ALD. For all types of samples, post deposition annealing (PDA) at $400^{\circ} \mathrm{C}$ in vacuum $\left(10^{-8}\right.$ Torr $)$ for 30 min was carried out. In all cases the oxide thicknesses were measured by ellipsometry and TEM microscopy. Further details about the samples can be found in our previous works, Refs. 19-21.

Regarding the electrical measurements, the capacitors were subjected to CVS where the gate current was measured as function of the time at different voltages using an Agilent
Parameter Analyzer 4155C with a resolution in time of some milliseconds. In all cases, the measurements were performed at room temperature $(300 \mathrm{~K})$, and the bias was applied on the gate with the other terminal (wafer's back contact) grounded. Further details about the measurements of the BD transient can be found in Refs. 1-3.

\section{RESULTS AND DISCUSSION}

Figure 1 shows a typical BD transient of gate current for metal gate $(\mathrm{MG}) / \mathrm{Al}_{2} \mathrm{O}_{3} / \mathrm{InGaAs}$ stacks, taken without applying a current compliance limit on the gate current, and observed under a CVS. Each curve corresponds to a different stress voltage ranging from $+5 \mathrm{~V}$ to $+6 \mathrm{~V}$. At least two distinctive phases can be observed in these curves. The first part, which is not a topic of this paper and was extensively studied in Ref. 19, is characterized by a decrease of the current due to negative charge trapping. Once the formation of one percolation path in the overall MOS capacitor sample is completed by generation of defects within the dielectric layer, the $\mathrm{BD}$ event takes place, and the gate current $\left(\mathrm{I}_{\mathrm{G}}\right)$ changes trend and starts increasing. ${ }^{1,3,13}$ It is a noisy and progressive process well in agreement with those reported in the literature for the cases of $\mathrm{HfO}_{2}{ }^{3,9,15}$ and $\mathrm{SiO}_{2}{ }^{1-3,16}$ The duration of the progressive increase of the current shows a strong voltage dependence and reaches current levels of the order of 1-10 $\mu \mathrm{A}$, where the gate current jumps abruptly to very high levels in times of the order of microseconds, i.e., limited by the bandwidth of the equipment (see Figure 1). It is worth to note that the current level where the gate current jumps abruptly is quite similar for all cases with different CVS voltages. Therefore, as reported in our previous work in Ref. 15, if the stress voltage or area is large enough to increase the background current above such a level, only a fast runaway will be observed. Figures 2 and 3 show some typical BD transients of gate currents for the $\mathrm{MG} / \mathrm{HfO}_{2}(10$ $\mathrm{nm}) / \mathrm{InGaAs}$ and the $\mathrm{MG} / \mathrm{Si}_{3} \mathrm{~N}_{4}(9 \mathrm{~nm}) / \mathrm{InGaAs}$ MOS stacks, respectively.

It is widely accepted that the evolution of the progressive BD current may be quantified by the slope of the current

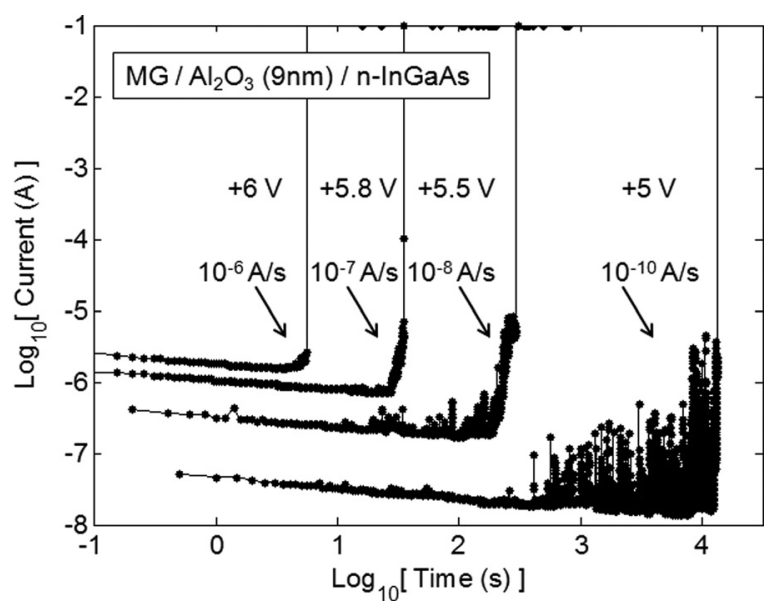

FIG. 1. Typical measurements of current as function of the time under constant voltage stress for the metal gate $/ \mathrm{Al}_{2} \mathrm{O}_{3}(9 \mathrm{~nm}) / \mathrm{n}-\mathrm{InGaAs}$ MOS stacks for constant voltage stress values ranging from $+5 \mathrm{~V}$ to $+6 \mathrm{~V}$. 


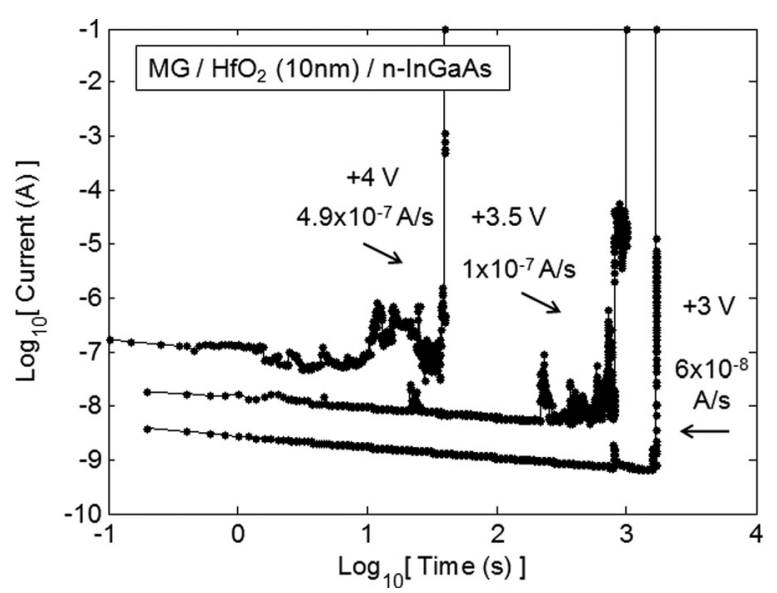

FIG. 2. Typical measurements of current as function of the time under constant voltage stress for the metal gate $/ \mathrm{HfO}_{2}(10 \mathrm{~nm}) / \mathrm{n}$-InGaAs MOS stacks for constant voltage stress values ranging from $+3 \mathrm{~V}$ to $+4 \mathrm{~V}$.

during the $\mathrm{BD}$ event $\left(\mathrm{I}_{\mathrm{BD}}\right)$, i.e., $\mathrm{dI}_{\mathrm{BD}} / \mathrm{dt}$, as defined in Ref. 1 . Figure 4 shows the $\mathrm{dI}_{\mathrm{BD}} / \mathrm{dt}$ values for different MOS stacks, calculated in the range of $1 \mathrm{nA}$ to $10 \mu \mathrm{A}$ (marked as "data"). The entire set of samples includes MOS capacitors with the same substrate (InGaAs), metal gate $(\mathrm{Au} / \mathrm{Ti})$, and oxide thickness, but different dielectrics: $\mathrm{Al}_{2} \mathrm{O}_{3}(9 \mathrm{~nm}), \mathrm{Si}_{3} \mathrm{~N}_{4}(9 \mathrm{~nm})$, and $\mathrm{HfO}_{2}(10 \mathrm{~nm})$. It also includes experimental data of poly-Si/ $/ \mathrm{SiO}_{\mathrm{x}} \mathrm{N}_{\mathrm{y}}(2 \mathrm{~nm}) / \mathrm{Si}$ from Refs. 1 and 13 (marked as "Linder" or "Lombardo", respectively). In the case of $\mathrm{SiO}_{\mathrm{x}} \mathrm{N}_{\mathrm{y}}$, the $\mathrm{dI}_{\mathrm{BD}} / \mathrm{dt}$ values at and above $10^{+2} \mathrm{~A} / \mathrm{s}$ of Ref. 13 are limited by the bandwidth of the experimental set-up. By using an experimental set-up with higher time resolution, it is shown that those data actually correspond to much faster BD transients. ${ }^{3}$ For this reason in Figure 4 , the data at $10^{+2} \mathrm{~A} / \mathrm{s}$ from Ref. 13 are shifted to higher values $\left(\geq 1 \times 10^{+6} \mathrm{~A} / \mathrm{s}\right)$.

Since the discussed effect is local, taking place only in the BD spot and not evenly distributed along the MOS area, it is important to note that gate area has no effect on $\mathrm{dI}_{\mathrm{BD}} / \mathrm{dt},{ }^{1,3}$ hence, the differences in the gate area of the devices used in this work will not affect neither the analysis nor the conclusions. It is clear from the figure that the data for $\mathrm{Al}_{2} \mathrm{O}_{3}$ and $\mathrm{Si}_{3} \mathrm{~N}_{4}$ are almost overlapping, while $\mathrm{HfO}_{2}$ and

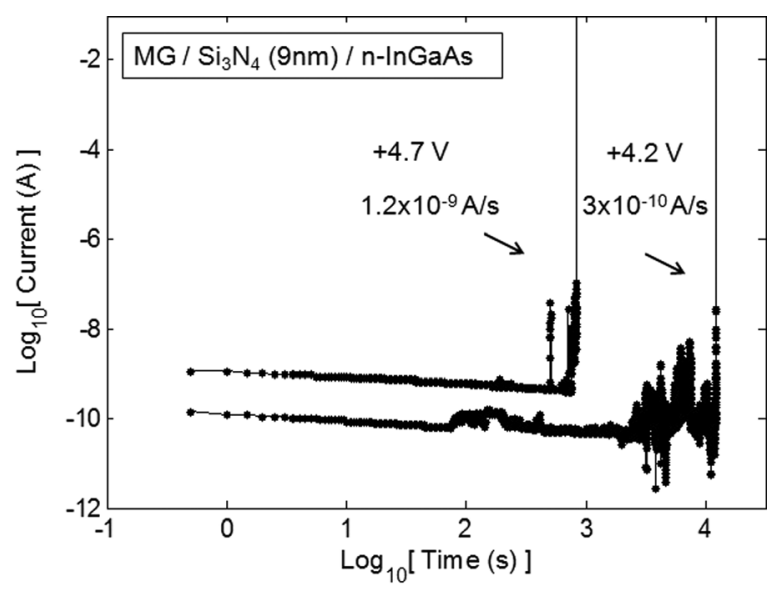

FIG. 3. Typical measurements of current as function of the time under constant voltage stress for the metal gate $/ \mathrm{Si}_{3} \mathrm{~N}_{4}(9 \mathrm{~nm}) / \mathrm{n}$-InGaAs MOS stacks for constant voltage stress values ranging from $+4.2 \mathrm{~V}$ to $+4.7 \mathrm{~V}$.

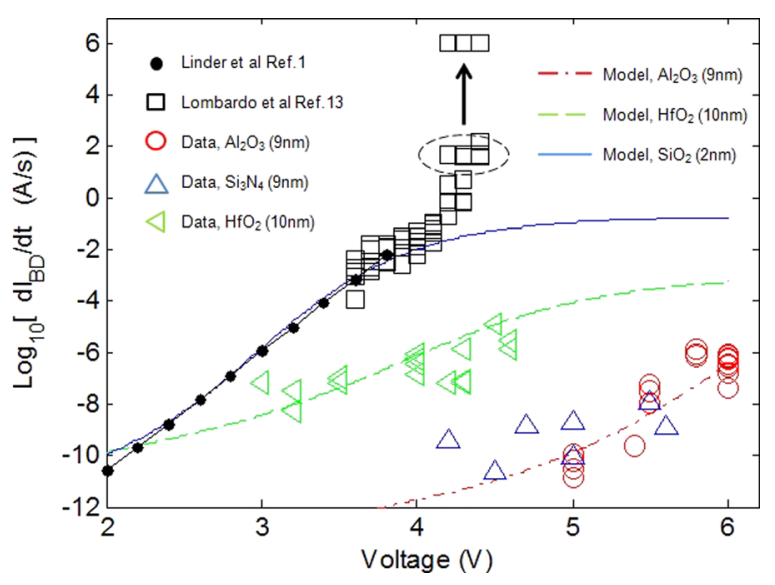

FIG. 4. Rate of the $\mathrm{BD}$ current increase, $\mathrm{dI}_{\mathrm{BD}} / \mathrm{dt}$, as function of the stress voltage measured in MOS stacks with different dielectrics. The symbols $\bigcirc$, $\triangle$, and $\triangleleft$, correspond to $\mathrm{Al}_{2} \mathrm{O}_{3}(9 \mathrm{~nm}), \mathrm{Si}_{3} \mathrm{~N}_{4}(9 \mathrm{~nm})$ and $\mathrm{HfO}_{2}(10 \mathrm{~nm})$, respectively. The experimental data of Poly-Si/SiON ( $2 \mathrm{~nm}) / \mathrm{Si}$ from Refs. 1 and 13, marked by and $\square$, respectively, and the calculations according to Eq. (3) are also included.

$\mathrm{SiO}_{\mathrm{x}} \mathrm{N}_{\mathrm{y}}$ show a faster progressive $\mathrm{BD}$, with an increased $\mathrm{dI}_{\mathrm{BD}} / \mathrm{dt}$ of 4 and 12 orders of magnitude respectively. A strong dependence on voltage is observed in all cases. The $\mathrm{dI}_{\mathrm{BD}} / \mathrm{dt}$ values reported in Figure 4 reflect the evolution of the current during the $\mathrm{BD}$ event observed experimentally. For example, in the case of $\mathrm{Al}_{2} \mathrm{O}_{3}$ (Fig. 1), the time to reach a current level of the order of $1 \mu \mathrm{A}$ ranges from few seconds at $+6 \mathrm{~V}$, up to $10^{+4}$ seconds at $+5 \mathrm{~V}$, while in the case of $\mathrm{HfO}_{2}$ (Fig. 2) the time to reach a current level of the order of $1 \mu \mathrm{A}$ ranges from a few seconds at $+4 \mathrm{~V}$ up to $10^{+3}$ seconds at $+3 \mathrm{~V}$. It is observed that the duration of the breakdown transient decreases dramatically for $\mathrm{HfO}_{2}$ even though the stress voltage is lower, and the oxide is slightly thicker. Such a drastically different behavior among these various dielectric layers raises the question about the cause of the difference.

It is worth to mention that the results of Figure 4 do not depend on the polarity of the stress voltage. A negative bias will only modify the degradation phase of the dielectric but not the duration of the progressive increase of the current. ${ }^{3}$

It is very important to compare our data measured on samples with InGaAs substrates with similar cases studied on samples with Si substrates. For example, the present case of the $\mathrm{HfO}_{2}$ gate dielectric can be compared with Ref. 15, referring to the case of a TiN/ $/ \mathrm{HfO}_{2} /$ interfacial $\mathrm{SiO}_{2} / \mathrm{Si}$ substrate, with a $2.5 \mathrm{~nm}$ thick $\mathrm{HfO}_{2}$ film and $1 \mathrm{~nm} \mathrm{SiO}_{2}$ layer. In this case, the $\mathrm{dI}_{\mathrm{BD}} / \mathrm{dt}$ values were of about $10^{-8}-10^{-10} \mathrm{~A} / \mathrm{s}$ at 2.5-3 V, very close to those reported here (Fig. 4). So, though the substrate material is very different ( $\mathrm{Si}$ vs. InGaAs), very similar $\mathrm{dI}_{\mathrm{BD}} / \mathrm{dt}$ values are found. We then conclude that the presence of $\mathrm{Si}$ atoms is not a requirement for the occurrence of the PBD phenomenon, since this is found with gate electrodes such as poly-Si or metal, with different gate oxides such as $\mathrm{SiO}_{2}, \mathrm{SiON}$, or high-k dielectrics, and even with different substrates such as $\mathrm{Si}$ or InGaAs. The basic physics of PBD is not related to some kind motion of silicon atoms, but rather another effect is playing the major role, as proposed in the model here presented. The similarities of $\mathrm{dI}_{\mathrm{BD}} / \mathrm{dt}$ values here found compared to Ref. 15 are 
well explained by the model we propose in the following part of the paper.

Since a high-k/InGaAs interface with a low density of defects is difficult to achieve and is currently under intensive investigation, ${ }^{19-22}$ one may argue that a poor structural quality is responsible for the results observed in Figure 4, particularly in the case of the relatively fast BD transient observed for the $\mathrm{HfO}_{2}$. In fact, we observe that the gate stack quality in terms of interface states, border traps, and leakage current affects only the first phase of the current-time measurements, and does not influence the progressive BD regime. ${ }^{3,19,23}$ In our samples, the initial defect density is sufficiently low and the MOS samples have to be stressed at high voltage for long times to increase the defect density within the dielectrics beyond the percolation threshold for $\mathrm{BD}^{24-26}$ in order to observe within reasonable times the onset of progressive $\mathrm{BD}$.

Since in Figure 4, the $\mathrm{dI}_{\mathrm{BD}} / \mathrm{dt}$ values are compared to those of ultra-thin $\mathrm{SiO}_{\mathrm{x}} \mathrm{N}_{\mathrm{y}}$ layers $(1.5-2.5 \mathrm{~nm})$, a more accurate way is to compare the data taking into account the oxide thickness dependence found by Linder et al. ${ }^{1}$ They report that the degradation rate increases by one order of magnitude for every $0.3 \mathrm{~nm}$ of scaling. ${ }^{1}$ By comparing Linder's data with our results of the $\mathrm{Al}_{2} \mathrm{O}_{3}$ films, which are $7 \mathrm{~nm}$ thicker, the difference in $\mathrm{dI}_{\mathrm{BD}} / \mathrm{dt}$ should be $7 / 0.3=23$ orders of magnitude. The direct comparison of the experimental data (Figure 4), however, gives a difference of only 9 orders of magnitude, far much smaller difference than expected. It is clear that simple data extrapolation is unable to predict the $\mathrm{dI}_{\mathrm{BD}} / \mathrm{dt}$ behavior. Therefore, a detailed physical understanding is necessary.

\section{ANALYSIS}

Summarizing the experimental results, as shown in Figure 4 , the behavior of the breakdown growth rate $\mathrm{dI}_{\mathrm{BD}} / \mathrm{dt}$ as a function of the gate voltage in the high permittivity dielectrics studied in this work, $\mathrm{Al}_{2} \mathrm{O}_{3}(9 \mathrm{~nm}), \mathrm{HfO}_{2}(10 \mathrm{~nm})$, $\mathrm{Si}_{3} \mathrm{~N}_{4}(9 \mathrm{~nm})$, ALD deposited on InGaAs substrates with a $\mathrm{Au} / \mathrm{Ti}(1 \mathrm{~nm})$ metal gate, is many orders of magnitude different compared to the well known baseline of poly-Si/SiO $\mathrm{N}_{\mathrm{y}} / \mathrm{Si}^{1,13}$ The high permittivity materials show a much lower $\mathrm{dI}_{\mathrm{BD}} / \mathrm{dt}$, implying a considerably improved reliability margins in CMOS applications compared to the Poly-Si/ $/ \mathrm{SiO}_{\mathrm{x}} \mathrm{N}_{\mathrm{y}} / \mathrm{Si}$ classical system. However, such an improvement is not as large as expected on the basis of the thickness dependence reported by Linder et al. ${ }^{1}$ Such an important experimental result calls for some basic understanding. We now propose a model which can explain such remarkable differences, and shows good agreement with the experimental results. The basic idea is that the progressive $\mathrm{BD}$ transient is due to an electro-migration effect providing atomic diffusion of the cathode or anode atoms into the gate dielectric in the region of the $\mathrm{BD}$ spot. A number of authors ${ }^{3,9,11,12}$ have shown that under $\mathrm{BD}$ conditions in poly-Si/SiO $\mathrm{N}_{\mathrm{y}} / \mathrm{Si}$ or in metal $/ \mathrm{HfO}_{2} / \mathrm{SiO}_{\mathrm{x}} \mathrm{N}_{\mathrm{y}} / \mathrm{Si}$ gate stacks the $\mathrm{BD}$ spot is characterized by the formation of a Si-rich (in the case of poly- $\mathrm{Si} / \mathrm{SiO}_{\mathrm{x}} \mathrm{N}_{\mathrm{y}} / \mathrm{Si}$ stacks), or a metal-rich region (in the case of metal gate/high-K/Si stacks) in the gate dielectric in correspondence with the BD spot. ${ }^{3,11,12}$ This is a clear evidence of atomic diffusion/electro-migration forming conductive channels/filaments in the gate dielectric. Moreover, the post-BD I-V characteristics under progressive $\mathrm{BD}$ are quite well explained by physical models invoking either co-tunneling $9,27,28$ or conductive filaments in the Landauer-Buttiker regime. ${ }^{29,30}$ These models postulate nanometric filaments or islands acting as stepping stones in the dielectric made of metallic or semiconducting materials. The reduced dimensionality and nanometric size of the filamen$\mathrm{t} /$ islands produce the relatively low conductance of the BD spot. For the model assuming embedded nanometric islands, the conductance regime which may explain the BD spot conductance is co-tunneling, ${ }^{28}$ close to the boundary of single electron tunneling. For the model assuming metallic filaments, the regime is that of a constriction of lateral size smaller than that accommodating the first 1D Landauer conductance channel. ${ }^{31}$ In both cases, the BD spot resistance is larger but close to the value of a quantum of resistance $\mathrm{R}_{\mathrm{Q}}=\mathrm{h} / \mathrm{q}^{2} \approx 25.8 \mathrm{k} \Omega$, with $\mathrm{q}$ being the elementary charge and $\mathrm{h}$ Plank constant. Note that $\mathrm{R}_{\mathrm{Q}}$ corresponds to a current of $\approx 100 \mu \mathrm{A}$ at $3 \mathrm{~V}$, relatively close to the conditions here experimentally studied.

Such current levels may trigger diffusion/electro-migration of atomic species in the BD spot, ${ }^{3,11}$ and this suggests a basic simple model to interpret the experimental results. According to Huntington ${ }^{32}$ and to Ho and Kwok, ${ }^{33}$ by following a theoretical approach of irreversible thermodynamics, the flux $\mathrm{J}_{\mathrm{EM}}$ of atoms moving by electro-migration is the sum of the gradients of the chemical potentials of the various atomic species present and of the electrostatic potential gradients weighted by suitable coefficients proportional to the relative atomic species diffusivities, plus crossed terms each proportional to the charge carrier flux (electron and hole fluxes) $\mathrm{J}$ times the atomic species diffusivity. In the cases investigated here, the BD conductance is most likely dominated by electrons, so we assume simply an electron flux (no holes). The model however can be simply extended to include the case of hole conduction.

Since $A_{B D}$ (area of the BD spot) is of the order of 1-50 $\mathrm{nm}^{2}, \mathrm{~J}$ is in the range of $200-10000 \mathrm{MA} / \mathrm{cm}^{2}$, i.e., a regime of intensive electro-migration. ${ }^{3,11,33}$ Given such large J values, we assume that simply one term, proportional to $\mathrm{D} \times \mathrm{J}$, where $\mathrm{D}$ is the fastest (dominant) diffusivity, is the main contribution to $\mathrm{J}_{\mathrm{EM}}$.

Let us derive the leading equation with some details. According to Ho and Kwok, ${ }^{33}$ the crossed-term linking the atomic flux $\mathrm{J}_{\mathrm{EM}}$ to the density of electrons transferring momentum to the diffusing metallic ions is

$$
J_{E M}=q^{2} \frac{N_{a t} D}{k_{B} T} n_{e} \lambda_{e} \sigma_{e} E
$$

where $\mathrm{E}$ is the electric field, $\mathrm{N}_{\mathrm{at}}$ is the atomic density of the metal, $\mathrm{D}$ is the atomic diffusivity, $\mathrm{k}_{\mathrm{B}}$ is the Boltzmann constant, $T$ is the temperature, $n_{e}$ is the electron density of the metal assumed to be the responsible for the intensive electro-migration taking place, $\lambda_{\mathrm{e}}$ is the electron mean free path, $\sigma_{\mathrm{e}}$ is the cross-section for the electron-atom collision, i.e., the basic mechanism responsible for the transfer of 
momentum from the conduction electron of the metal to the diffusing atom and therefore of the electro-migration. As mentioned above, the $\mathrm{I}-\mathrm{V}$ characteristics under progressive $\mathrm{BD}$ are quite well explained by well known physical models, for example, by invoking co-tunneling. 9,27,28 According to this, it is easy to show that $\mathrm{I}_{\mathrm{BD}}$ is given by the product $\mathrm{C}_{1}(\mathrm{~A}) \times \mathrm{C}_{2}\left(\mathrm{~V}, \mathrm{t}_{\mathrm{ox}}\right)$ where $\mathrm{C}_{1}$ is a monotonically increasing function of $\mathrm{A}$, the $\mathrm{BD}$ spot base area, and $\mathrm{C}_{2}$ is a function of $\mathrm{V}$, the voltage, and $\mathrm{t}_{\mathrm{ox}}$, the oxide thickness. In particular, in the co-tunneling regime with low conductance $\mathrm{C}_{1}$ is equal to $\mathrm{A}^{\alpha}$, with $\alpha=4$. From such power law dependence it follows that $\frac{d I_{B D}}{d t}=\frac{\alpha I_{B D}}{A} \frac{d A}{d t}$. As the BD spot area A grows, the BD becomes harder, i.e., $\mathrm{I}_{\mathrm{BD}}$ increases, and so it approaches the simpler Ohm's law limit where, by assuming a cylindrical geometry for the BD filament, $\frac{d I_{B D}}{d t}=\frac{V}{\rho t_{o x}} \frac{d A}{d t}=\frac{I_{B D}}{A} \frac{d A}{d t}$, where $\rho$ is the metal resistivity. Namely, we obtain the same expression as above but with $\alpha=1$.

So we can in general assume that

$$
\frac{d I_{B D}}{d t}=\frac{\alpha I_{B D}}{A} \frac{d A}{d t}
$$

and for simplicity we take $\alpha=1$.

For mass conservation the BD spot growth is due to the flux $\mathrm{J}_{\mathrm{EM}}$, i.e., $\frac{d A}{d t}=\frac{J_{E M}}{q} \frac{A}{t_{o r} N_{a t}}$. So, by using Eqs. (1) and (2), and with some straightforward re-writing one finds the following very concise equation

$$
\frac{d I_{B D}}{d t}=\frac{q V}{k_{B} T} \frac{f_{1}}{t_{o x}^{2}} D I_{B D},
$$

where $f_{1}=n_{e} \lambda_{e} \sigma_{e}$. Clearly $\mathrm{f}_{1}$ is larger or equal to 1 , but of the order of 1 since the defect concentration in the metallic filament is most likely very high. Equation (3) satisfies the experimental finding of Linder et al. ${ }^{1}$ that $\mathrm{dI}_{\mathrm{BD}} / \mathrm{dt}=\mathrm{I}_{\mathrm{BD}} / \tau$, where $\tau$ is a time constant. In addition, Eq. (3) gives a direct physical explanation for $\tau$.

According to Eq. (3), $\mathrm{dI}_{\mathrm{BD}} / \mathrm{dt}$ is proportional to $\mathrm{D} \times \mathrm{I}_{\mathrm{BD}}$. This means that the BD growth rate grows either by increasing the charge carrier (usually electron) flux or by increasing the dominant diffusivity $\mathrm{D}$ of the fastest atomic species. The particular species may change, depending on the system. It may consist of $\mathrm{Si}$ atoms, or metal atoms coming from the gates, etc, as suggested by the electron microscopy studies on the BD spot nanostructure..$^{3,11,12,34,35}$ There is also a strong dependence on $\mathrm{t}_{\mathrm{ox}}$, and on $\mathrm{V}$ and $\mathrm{T}$. So, according to Eq. (3), since $\mathrm{V}, \mathrm{T}$, and $\mathrm{t}_{\mathrm{ox}}$ are known, to evaluate $\mathrm{dI}_{\mathrm{BD}} / \mathrm{dt}$ we need to model the two parameters $\mathrm{I}_{\mathrm{BD}}$ and $\mathrm{D}$. $\mathrm{I}_{\mathrm{BD}}$ is quite well described by the models mentioned above assuming co-tunneling of charge carriers due to one or few conductive islands embedded in the gate dielectric in correspondence with the BD spot $^{9,11}$ or a quantum size metallic filament modeled according to the Landauer-Buttiker formalism. ${ }^{29,30}$ These models contain numerous parameters, the values of which are difficult to predict and require data fitting. To simplify the approach, we have preferred to model the BD spot $\mathrm{I}_{\mathrm{BD}}-\mathrm{V}$ curve by assuming the following simple analytical dependence:

$$
\mathrm{I}_{\mathrm{BD}}=\mathrm{I}_{1} \exp \left[\log \left(\frac{\mathrm{I}_{2}}{\mathrm{I}_{1}}\right)\left(\frac{\mathrm{V}-\mathrm{V}_{1}}{\mathrm{~V}_{2}-\mathrm{V}_{1}}\right)^{\alpha}\right]
$$

where $I_{1}, I_{2}, V_{1}, V_{2}$, and $\alpha$ are parameters chosen by best fit to the experimental $\mathrm{I}_{\mathrm{BD}^{-}} \mathrm{V}$ data. To determine the parameters we choose two points $\left(\mathrm{I}_{1}, \mathrm{~V}_{1}\right)$ and $\left(\mathrm{I}_{2}, \mathrm{~V}_{2}\right)$ in the experimental $\mathrm{I}_{\mathrm{BD}^{-}} \mathrm{V}$ curve at low and high voltage, respectively, and we set $\alpha$ by data fitting. Figure 5 shows typical experimental data of the current-voltage characteristics of the BD spot during the PBD regime for $\mathrm{HfO}_{2}$ and $\mathrm{Al}_{2} \mathrm{O}_{3}$. At low voltages, the $\mathrm{I}_{\mathrm{BD}}-\mathrm{V}$ curves were measured after interrupting the CVS, in between one stress and the following, while at high voltages, the current level of $\mathrm{I}_{\mathrm{BD}}$ was determined just before the abrupt jump to very high levels (Figure 1) for different values of CVS bias. Figure 5 also shows the comparison of the experimental data with the model of Eq. (4), indicating that the best fit to the experimental data is generally found for $\alpha \approx 0.5$.

To model $\mathrm{D}$, we need first to model the temperature in the BD spot and for that we need to solve the heat diffusion equation. We make a strong simplification of spherical symmetry around an inner sphere of radius $r_{1}$ in which there is a source power density $\mathrm{q}_{1}$ constant over the inner sphere surface. $\mathrm{q}_{1}$ is the electrical power, dissipated in heat, proportional to $\mathrm{I}_{\mathrm{BD}} \times \mathrm{V}$ at the $\mathrm{BD}$ spot center. This assumption is reasonable: for example, Takagi et al. ${ }^{36}$ have shown that the electrons tunneling through defects responsible for stress induced leakage current (SILC) in thin oxynitrides do lose a large fraction of their energy in the oxide. That is, the electron tunneling through SILC defects is inelastic, with a large fraction of electron energy lost due to defect relaxation, as shown by Blöchl and Stathis. ${ }^{37}$ It is reasonable to assume that a similar effect takes place during electron transport through the BD spot. The other boundary condition for the heat diffusion equation concerns the temperature at an outer

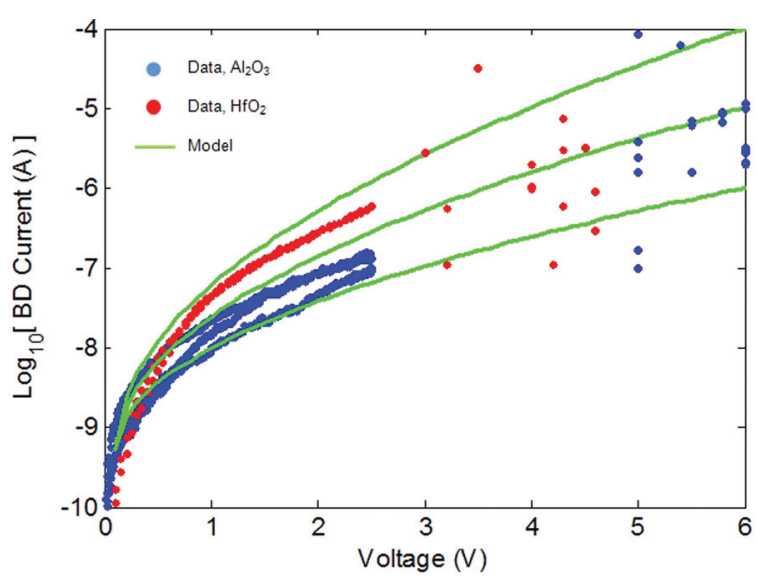

FIG. 5. Typical experimental data of the current-voltage characteristics of the $\mathrm{BD}$ spot during the $\mathrm{PBD}$ regime for $\mathrm{HfO}_{2}$ and $\mathrm{Al}_{2} \mathrm{O}_{3}$. At low voltages, the $\mathrm{I}_{\mathrm{BD}}-\mathrm{V}$ curves are measured after interrupting the CVS, in between one stress and the following, while at high voltages, the current level of IBD is determined just before the abrupt jump to very high levels (Figure 1) for different values of CVS bias. The continuous curves are the calculation according the model of Eq. (4), indicating that the best fit to the experimental data is generally found for $\alpha=0.5$. 
sphere of radius $r_{2}$, set constant and equal to $T_{2}$, the ambient temperature $T_{a m b}$. Then, for $r_{1}<r<r_{2}$ the temperature $T(r)$ is

$$
T(r)=\frac{q_{1} r_{1}^{2}}{\kappa}\left(\frac{1}{r}-\frac{1}{r_{2}}\right)+T_{2},
$$

where $\kappa$ is the thermal conductivity of the dielectric, with the further simplifying assumption of neglecting the thermal influence of the other materials present in the gate stack.

We assume that $q_{1}=\frac{f_{2} V I_{B D}}{4 \pi r_{1}^{2}}$ where $\mathrm{f}_{2}$ is the fraction of the energy $q V$ per electron lost at the BD spot, that $r_{1}=t_{o x} / 2$ and that $r_{1} \ll r_{2}$. Then at a distance $r=r_{1}$ from the source of the diffusing atoms contributing to the BD spot growth, according to Eq. (5) the temperature $\mathrm{T}$ is

$$
T=\frac{f_{2} V I_{B D}}{2 \pi t_{o x} \kappa}+T_{a m b},
$$

where $\mathrm{T}$ is the local temperature at the electrode which provides the dominant diffusing atomic species, at the boundary with the BD spot. Then, the diffusivity $\mathrm{D}$ is simply $\mathrm{D}=\mathrm{D}_{0} \exp \left(-\mathrm{E}_{\mathrm{act}} / \mathrm{k}_{\mathrm{B}} \mathrm{T}\right)$, where $\mathrm{D}_{0}$ is a pre-exponential term, and $\mathrm{E}_{\mathrm{act}}$ is the diffusion activation energy.

We have applied this model (Eqs. (3), (4), (6), and $\left.\mathrm{D}=\mathrm{D}_{0} \exp \left(-\mathrm{E}_{\mathrm{ac}} / \mathrm{k}_{\mathrm{B}} \mathrm{T}\right)\right)$ to fit the experimental data of $\mathrm{dI}_{\mathrm{BD}} / \mathrm{dt}$ vs. gate voltage reported in Figure 4 for a number of MOS systems: Poly-Si/ $\mathrm{SiO}_{\mathrm{x}} \mathrm{N}_{\mathrm{y}} / \mathrm{Si}$ (from Refs. 1 and 13), taken as baseline, compared to the high permittivity dielectrics studied in this work: $\mathrm{Al}_{2} \mathrm{O}_{3}(9 \mathrm{~nm}), \mathrm{HfO}_{2}(10 \mathrm{~nm})$, $\mathrm{Si}_{3} \mathrm{~N}_{4}(9 \mathrm{~nm})$, ALD deposited on InGaAs substrates with a $\mathrm{Au} / \mathrm{Ti}(1 \mathrm{~nm})$ metal gate.

Clearly such a fit cannot accurately establish the parameter values, but rather it allows to find the order of magnitude of the various parameters. The fit parameters are in fact four: $E_{\text {act }}, D_{0}, f_{1}$, and $f_{2}$. The other five $I_{1}, V_{1}, I_{2}, V_{2}$, and $\alpha$ are directly quite accurately evaluated by comparison with the experimental $\mathrm{I}_{\mathrm{BD}^{-}}-\mathrm{V}$ curves of the BD spot (such as Figure 5). In all cases, as shown by comparison of Eq. (4) with the data reported in Figure 5, $\alpha$ can be estimated to be 0.5. The thermal conductivities $\kappa$ are not fit parameters and have been taken from the literature. The values are reported in Table I. It is important to emphasize the very different values of $\kappa$ explored in this work.

The $\mathrm{f}_{1}$ parameter (where $f_{1}=n_{e} \lambda_{e} \sigma_{e}$ ) has been fixed in all cases to be 1 . This is a reasonable assumption; by considering the fact that the BD spot metallic filament is most likely a densely defect populated material, so $\mathrm{f}_{1} \approx 1 . \mathrm{f}_{2}$

\begin{tabular}{|c|c|c|c|c|c|}
\hline $\begin{array}{l}\text { Dielectric } \\
\text { layer }\end{array}$ & $\varepsilon_{\mathrm{ox}}^{\mathrm{a}}$ & $\begin{array}{c}\text { Thermal } \\
\text { conductivity }^{\mathrm{b}} \\
{[\mathrm{W} / \mathrm{m} \mathrm{K}]}\end{array}$ & $\begin{array}{l}\text { Melting } \\
\text { temperature }[\mathrm{K}]\end{array}$ & Substrate & Gate \\
\hline $\mathrm{Al}_{2} \mathrm{O}_{3}$ & $\sim 10$ & 30 & 2300 & InGaAs & $\mathrm{Au}$ \\
\hline $\mathrm{Si}_{3} \mathrm{~N}_{4}$ & 7 & $\sim 30$ & 2100 & InGaAs & $\mathrm{Au}$ \\
\hline $\mathrm{HfO}_{2}$ & $\sim 20$ & 1.1 & 3000 & InGaAs & $\mathrm{Au}$ \\
\hline $\mathrm{SiO}_{2}$ & 3.9 & 1.4 & 1900 & $\mathrm{Si}$ & Poly-Si \\
\hline
\end{tabular}

TABLE I. Description of samples studied.

${ }^{\mathrm{a}}$ Reference 42.

${ }^{\mathrm{b}}$ References 43-47. (the fraction of the energy per electron dissipated in the dielectric as heat at the BD spot) has been assumed to be 0.5 in the cases of $\mathrm{Al}_{2} \mathrm{O}_{3}, \mathrm{Si}_{3} \mathrm{~N}_{4}$, and $\mathrm{HfO}_{2}$, and 0.25 in the case of $\mathrm{SiO}_{\mathrm{x}} \mathrm{N}_{\mathrm{y}}$. The chosen value for $\mathrm{SiO}_{\mathrm{x}} \mathrm{N}_{\mathrm{y}}$ has been estimated by considering the results of Takagi et $a l^{36}$ on SILC loss, while the larger value assumed for the high-K materials has been taken to consider the larger thickness (about $10 \mathrm{~nm}$ for the high-K materials vs. $2 \mathrm{~nm}$ for the $\mathrm{SiO}_{\mathrm{x}} \mathrm{N}_{\mathrm{y}}$ ). So, in fact, in the chosen fit conditions, there are only two parameters to fit, those describing the atom diffusivity $\mathrm{D}$, i.e., $\mathrm{E}_{\text {act }}$ and $\mathrm{D}_{0}$. The model provides a quite good fit to the experimental data, as shown in Figure 4. In all the cases the best fit diffusivities are quite large, of the of order of $10^{-13} \mathrm{~cm}^{2} / \mathrm{s}$ at $1000 \mathrm{~K}$, with low activation energies ranging from 0.7 to $0.3 \mathrm{eV}$. Such large D values may be reasonable by considering that the diffusivity is evaluated under high electric field application. It has been found that the diffusivity of metals ions in dielectrics $\left(\mathrm{SiO}_{2}\right)$ is strongly influenced by the electric field strength. In conditions comparable to those here studied, the diffusivities of metals in dielectrics are in a range coincident to that here reported, ${ }^{38-41}$ see for example, the case of $\mathrm{Cu}$ diffusion into $\mathrm{SiO}_{2}$ layers. ${ }^{41}$

The very different behaviour of the various materials shown in Figure 4 is explained by the very different combinations of $\mathrm{t}_{\mathrm{ox}}$ and $\kappa$ in the various cases. Note in particular the cases of $\mathrm{Si}_{3} \mathrm{~N}_{4}, \mathrm{Al}_{2} \mathrm{O}_{3}$, and $\mathrm{HfO}_{2}$, which share the same type of metal gate and substrate, and have essentially the same $t_{\mathrm{ox}}$. Nevertheless $\mathrm{HfO}_{2}$ shows a much lower $\mathrm{dI}_{\mathrm{BD}} / \mathrm{dt}$. The only main difference is $\kappa$, and this results in a completely different behaviour of $\mathrm{dI}_{\mathrm{BD}} / \mathrm{dt}$, well explained by the model (Eq. (6)). On the contrary, $\mathrm{Si}_{3} \mathrm{~N}_{4}$ and $\mathrm{Al}_{2} \mathrm{O}_{3}$, which have similar thermal conductivity, show very similar $\mathrm{dI}_{\mathrm{BD}} / \mathrm{dt}$.

At large voltages/currents the BD spot temperature estimated through the present model exceeds $1000-2000 \mathrm{~K}$, i.e. local melting of the gate stack takes place. This voltage/ current/temperature region is clearly beyond the range of applicability of the present model since a solid-liquid phase transition takes place, and it is where the $\mathrm{dI}_{\mathrm{BD}} / \mathrm{dt}$ vs. $\mathrm{V}$ model curve starts to saturate. So, the saturation region of the model curves of Figure 4 is beyond the model validity range and has no meaning.

\section{SUMMARY AND CONCLUSIONS}

In this paper, we have shown that the progressive BD event occurs in the case of metal gates, high-K dielectrics and InGaAs substrates. Therefore, taking into account previous literature we find that the progressive BD in MOS structures occurs with Poly-Si or metal gate electrodes, with $\mathrm{SiO}_{2}$, $\mathrm{SiO}_{\mathrm{x}} \mathrm{N}_{\mathrm{y}}$ or high-k dielectrics as gate oxides, and with $\mathrm{Si}$ or InGaAs substrates. Namely, it is a very general physical effect which does not necessarily requires the motion of Si atoms.

We therefore propose that the PBD is due to the energy transfer from the BD path to its surroundings which promotes electro-migration of the fastest atomic species among those available, providing the build-up of the BD filament. Our results unambiguously relate the breakdown growth rate $\mathrm{dI}_{\mathrm{BD}} / \mathrm{dt}$ to heat dissipation properties during the atomic diffusion of the cathode or anode atoms into the gate dielectric in 
the region of the percolation path. In dielectrics layers with higher thermal conductivity the power dissipated in the vicinity of the BD spot can be transferred to the environment at a speed large enough to maintain the temperature low, and, hence, to decrease the breakdown growth rate. The model proposed in this work captures the main physical mechanisms responsible for the progressive increase of the current when a gate dielectric loses its insulating properties. This physical interpretation provides a quite good fit to the experimental data with only two free parameters, related to the diffusivity of the faster atomic diffuser present in the gate stack (substrate, dielectric, and gate). The demonstrated ability to reduce the breakdown growth rate $\mathrm{dI}_{\mathrm{BD}} / \mathrm{dt}$ in MOS structures by increasing the thermal conductivity of the gate oxides is a key for improving considerably the reliability margins in CMOS applications. Besides their relevance for the scaling of gate dielectrics of transistors in modern CMOS integrated circuits, our results may provide a basic framework also for different applications of ultra-thin dielectrics, in particular for the electrically induced resistive switching effects which have been proposed as the basis for future semiconductor non-volatile memories.

\section{ACKNOWLEDGMENTS}

The authors gratefully acknowledge Krylov I. (Technion) for providing the samples. P.F. is a researcher of CONICET on leave at the Technion. This work was supported by the European Union's-Seventh Framework Programme (FP7/2007-2013) under Grant Agreement No. 299094-MC-CONAT.

${ }^{1}$ B. P. Linder, S. Lombardo, J. H. Stathis, A. Vayshenker, and D. J. Frank, IEEE Electron Device Lett. 23(11), 661 (2002).

${ }^{2}$ F. Monsieur, E. Vincent, D. Roy, S. Bruyere, J. C. Vildeuil, G. Pananakakis, and G. Ghibaudo, IEEE Int. Reliab. Phys. Symp. 2002, 45.

${ }^{3}$ S. Lombardo, J. H. Stathis, B. P. Linder, K. L. Pey, F. Palumbo, and C. H. Tung, J. Appl. Phys. 98, 121301 (2005).

${ }^{4}$ R. Waser and M. Aono, Nature Mater. 6, 833 (2007).

${ }^{5}$ E. Linn, R. Rosezin, C. Kügeler, and R. Waser, Nature Mater. 9, 403 (2010). ${ }^{6}$ M. A. Alam, R. K. Smith, B. E. Weir, and P. J. Silverman, Nature 420, 378 (2002).

${ }^{7}$ B. P. Linder and J. H. Stathis, Microelectron. Eng. 72, 24 (2004).

${ }^{8}$ J. Suñé, E. Y. Wu, D. Jimenez, R. P. Vollersten, and E. Miranda, IEEE Int. Electron Dev. Meet. 2001, 117.

${ }^{9}$ G. Condorelli, S. Lombardo, F. Palumbo, K. L. Pey, C. H. Tung, and L. J. Tang, IEEE Trans. Device Mater. Reliab. 6(4), 534 (2006).

${ }^{10} \mathrm{X}$. Li, C. H. Tung, and K. L. Pey, Appl. Phys. Lett. 93, 072903 (2008).

${ }^{11}$ C. H. Tung, K. L. Pey, L. J. Tang, M. K. Radhakrishnan, W.-H. Lin., F. Palumbo, and S. Lombardo, Appl. Phys. Lett. 83(1), 2223 (2003).

${ }^{12}$ F. Palumbo, G. Condorelli, S. Lombardo, K. L. Pey, C. H. Tung, and L. J. Tang, Microelectron. Reliab. 45, 845 (2005).

${ }^{13}$ S. Lombardo, J. H. Stathis, and B. P. Linder, Phys. Rev. Lett. 90(16), 167601 (2003)

${ }^{14}$ S. Lombardo, A. La Magna, I. Crupi, C. Gerardi, and F. Crupi, Appl. Phys. Lett. 79, 1522 (2001).
${ }^{15}$ R. Pagano, S. Lombardo, F. Palumbo, P. Kirsch, S. A. Krishnan, C. Young, R. Choi, G. Bersuker, and J. H. Stathis, Microelectron. Reliab. 48(11-12), 1759 (2008).

${ }^{16}$ F. Palumbo, S. Lombardo, J. H. Stathis, V. Narayanan, F. R. McFeely, and J. J. Yurkas, IEEE Int. Reliab. Phys. Symp. 2004, 122.

${ }^{17}$ S. Lombardo and F. Palumbo, in 208th ECS Meeting (2005), p. 740.

${ }^{18}$ G. Bersuker, N. Chowdhury, C. Young, D. Heh, D. Misra, and R. Choi, IEEE Int. Reliab. Phys. Symp. 2007, 49.

${ }^{19}$ F. Palumbo and M. Eizenberg, J. Appl. Phys. 115, 014106 (2014).

${ }^{20}$ I. Krylov, A. Gavrilov, S. Cohen, D. Ritter, and M. Eizenberg, ECS Trans. 41(3), 255 (2011).

${ }^{21}$ I. Krylov, A. Gavrilov, M. Eizenberg, and D. Ritter, Appl. Phys. Lett. 101, 063504 (2012).

${ }^{22}$ J. A. del Alamo, Nature 479, 317 (2011).

${ }^{23}$ J. H. Stathis, IBM J. Res. Dev. 46(2/3), 265 (2002).

${ }^{24}$ J. H. Stathis, J. Appl. Phys. 86, 5757 (1999).

${ }^{25}$ J. Suñé, I. Placencia, N. Barniol, E. Farrés, F. Martín, and X. Aymerich, Thin Solid Films 185, 347 (1990).

${ }^{26}$ R. Degraeve, G. Groeseneken, R. Bellens, J. L. Ogier, M. Depas, P. J. Rousseland, and H. E. Maes, IEEE Trans. Electron Devices 45(4), 904 (1998).

${ }^{27}$ T. Nigam, S. Martin, and D. Abusch-Magder, IEEE Int. Reliab. Phys. Symp. 2003, 417.

${ }^{28}$ D. Ferry and S. Goodnick, Transport in Nanostructures, in Cambridge Studies in Semiconductor Physics and Microelectronic Engineering (Cambridge Univ. Press, Cambridge, U.K., 2000).

${ }^{29}$ E. Miranda and J. Suñé, IEEE Int. Reliab. Phys. Symp. 2001, 367.

${ }^{30}$ E. Miranda and J. Suñé, Microelectron. Reliab. 44(1), 1 (2004).

${ }^{31}$ S. Datta, Electronic Transport in Mesoscopic Systems (Cambridge University Press, Cambridge, U.K., 1997).

${ }^{32}$ H. B. Huntington, in Diffusion in Solids: Recent Developments, edited by A. S. Nowick and J. J. Burton (Academic Press, New York, USA, 1974), Chap. 6.

${ }^{33}$ P. S. Ho and T. Kwok, Rep. Prog. Phys. 52, 301 (1989).

${ }^{34}$ S. Privitera, G. Bersuker, B. Butcher, A. Kalantarian, S. Lombardo, C. Bongiorno, R. Geer, D. C. Gilmer, and P. D. Kirsch, Microelectron. Eng. 109, 75 (2013).

${ }^{35}$ S. Privitera, G. Bersuker, B. Butcher, S. Lombardo, C. Bongiorno, D. C. Gilmer, and P. D. Kirsch, "Conductive filament structure in $\mathrm{HfO}_{2} \mathrm{ReRAM}$ devices," in Proceedings of the 18th Workshop on Dielectrics in Microelectronics (to be published).

${ }^{36}$ S. Takagi, N. Yasuda, and A. Toriumi, IEEE Trans Electron Devices 46(2), 335 (1999).

${ }^{37}$ P. E. Blöchl and J. H. Stathis, Phys. Rev. Lett. 83, 372 (1999).

${ }^{38}$ L. A. Nesbit, Appl. Phys. Lett. 46(1), 38 (1985).

${ }^{39}$ J. D. McBrayer, R. M. Swanson, and T. W. Sigmon, J. Electron. Chem. Soc. 133(6), 1242 (1986).

${ }^{40}$ S. P. Murarka, I. V. Verner, and R. J. Gutmann, Copper-Fundamental Mechanisms for Microelectronic Applications (John Wiley \& Sons, Inc., New Jersey, USA, 2000).

${ }^{41}$ Y. Shacham-Diamand, A. Dedhia, D. Hoffstetter, and W. G. Oldham, J. Electron. Chem. Soc. 140(8), 2427 (1993).

${ }^{42}$ H.-S. P. Wong, IBM J. Res. Dev. 46(2/3), 133 (2002).

${ }^{43}$ See www.nist.gov/srd/onlinelist.cfm for NIST Standard Reference Database.

${ }^{44}$ M. Miyayama, K. Koumotoand, and H. Yanagida, "Engineering properties of single oxides," in Engineered Materials Handbook, edited by S. J. Schneider (CRC Press, 1991), Vol. 4, p. 748.

${ }^{45}$ S. Hampshire, Engineering Properties of Nitrides in Engineered Materials Handbook, edited by S. J. Schneider (CRC Press, 1991), Vol. 4, pp. 812-820.

${ }^{46}$ M. A. Panzer, M. Shandalov, J. A. Rowlette, Y. Oshima, W.-C. Yi, P. C. McIntyre, and K. E. Goodson, IEEE Electron Device Lett. 30(12), 1269 (2009).

${ }^{47}$ S. M. Sze, Physics of Semiconductor Devices (John Wiley \& Sons, New York, USA, 1981). 